\section{The journey to femtosecond laser-assisted cataract surgery: new beginnings or a false dawn?}

\begin{abstract}
Femtosecond laser-assisted cataract surgery (FLACS) represents a potential paradigm shift in cataract surgery, but it is not without controversy. Advocates of the technology herald FLACS as a revolution that promises superior outcomes and an improved safety profile for patients. Conversely, detractors point to the large financial costs involved and claim that similar results are achievable with conventional small-incision phacoemulsification. This review provides a balanced and comprehensive account of the development of FLACS since its inception. It explains the physiology and mechanics underlying the technology, and critically reviews the outcomes and implications of initial studies. The benefits and limitations of using femtosecond laser accuracy to create corneal incisions, anterior capsulotomy, and lens fragmentation are explored, with reference to the main platforms, which currently offer FLACS. Economic considerations are discussed, in addition to the practicalities associated with the implementation of FLACS in a healthcare setting. The influence on surgical training and skills is considered and possible future applications of the technology introduced. While in its infancy, FLACS sets out the exciting possibility of a new level of precision in cataract surgery. However, further work in the form of large scale, phase 3 randomised controlled trials are required to demonstrate whether its theoretical benefits are significant in practice and worthy of the necessary huge financial investment and system overhaul. Whether it gains widespread acceptance is likely to be influenced by a complex interplay of scientific and socio-economic factors in years to come.
\end{abstract}

Eye (2013) 27, 461-473; doi:10.1038/eye.2012.293; published online 1 February 2013
S Trikha1', AMJ Turnbull², RJ Morris', DF Anderson ${ }^{1,3}$ and $P$ Hossain ${ }^{1,3}$
Keywords: cataract surgery; femtosecond; laser; capsulorhexis; capsulotomy; phacoemulsfication

\section{Introduction}

Femtosecond laser-assisted cataract surgery (FLACS) represents a potential paradigm shift in cataract surgery, but has also generated considerable controversy. Advocates of the technology suggest that the use of femtosecond laser precision will deliver superior outcomes, an improved safety profile for patients and pave the way for further advances in the field. Conversely, detractors point to the large financial costs involved and claim that similar results are achievable with conventional smallincision phacoemulsification.

\section{Materials and methods}

A literature search was undertaken on Pubmed using the following investigative terms: 'femtosecond', 'phacoemulsification', 'cataract', 'ultrafast', 'laser', and combinations thereof.

Search results were screened for relevance, and only English language papers published up to October 2012 were included. References cited by these papers were also retrieved and analysed. In addition, articles and scientific papers from the authors' personal libraries were reviewed.

This review provides a thorough and unbiased account of the development of FLACS since its inception, assessing, and appraising the current evidence.
${ }^{1}$ Eye Unit, University Hospital Southampton Foundation Trust Southampton, UK

${ }^{2}$ Department of Ophthalmology, Salisbury District Hospital, Salisbury, UK

${ }^{3}$ Clinical and Experimental Sciences, Faculty of Medicine, University of Southampton, Southampton, UK

Correspondence: PN Hossain, Eye Unit, University Hospital Southampton Foundation Trust, MP104, Tremona Road, Southampton SO16 6YD, UK.

Tel: + 44 (0)23 8077 7222;

Fax: + 44 (0)23 80794120

E-mail: parwez@soton.ac.uk

Received: 10 October 2012 Accepted in revised form: 15 December 2012 Published online: 1 February 2013 


\section{Historical perspective-the evolution of cataract surgery}

The first references to cataract surgery were made by the scholar Aulus Celcius in 29 AD. Around 200 AD, the Indian physician Sushruta described the surgical procedure of couching, illustrating an operation whereby the eye was punctured using a 'barley-shaped tipped rod-like instrument held with the middle, index, and thumb fingers.' In the 18th century, cataract surgery reached Europe, but it was not until the 1948, through Harold Ridley and the concept of intraocular lens implantation permitting rapid visual rehabilitation, that giant strides in surgical technique were made. In 1967, when Charles Kelman introduced phacoemulsification, the need for a long postoperative stay in hospital reduced, but this was not adopted widely in the United Kingdom until the 1990s.

Since its inception, phacoemulsification surgery has accelerated through improved instruments, lens technology, fluidics, and energy delivery. ${ }^{1}$ Nevertheless, the basic series of steps involved have remained largely unchanged over the past 20 years. $^{2}$

Today, cataract surgery is the most commonly performed surgical procedure in the world, with an estimated 19 million operations performed annually. ${ }^{1}$ In the United Kingdom alone, it is estimated that 300000 operations are performed per year by the National Health Service (NHS).

\section{Lasers in cataract surgery}

During the 1970s, lasers began to be investigated and developed for a variety of different applications within the arena of cataract surgery. The most widely adopted is the neodymium-doped yttrium-aluminium-garnet (Nd:YAG) laser for posterior capsulotomy in pseudophakic patients with posterior capsular opacification, a technique first described in $1980 .{ }^{3}$ Lasers have also been employed for phacopuncture, ${ }^{4}$ anterior capsulotomy before cataract extraction ${ }^{5}$ and photolysis of the cataractous lens. ${ }^{6,7}$ However, owing to either undesirable complications or simply a preference for other non-laser-based techniques, these applications are not in common usage.

Ultrafast femtosecond laser (FSL) technology was introduced in 2001, ${ }^{8}$ revolutionising corneal flap creation in laser in situ keratomileusis (LASIK). This has resulted in more predictable and accurate flaps with a lower frequency of complications. The number of corneal refractive procedures performed so far using FSL is estimated at over two million ${ }^{9}$ and newer generation FSL systems continue to evolve in terms of both precision and versatility. It is postulated that FSL technology can produce the same gains in cataract surgery as it promises to improve accuracy, reproducibility, and safety beyond what is currently possible. ${ }^{10}$ It has even been stated that FLACS may herald, 'the most important evolution since the transition to phacoemulsification. ${ }^{11}$

\section{FLACS: physiology and mechanics}

\section{The femtosecond laser}

Femtosecond lasers are advantageous for two key reasons. First, the $1053 \mathrm{~nm}$ wavelength is in the nearinfrared spectrum, which is not absorbed by optically clear tissues at low power densities ${ }^{12}$ and is unaffected by corneal magnification. To a certain extent, it can also transmit through optically denser media such as oedematous or mildly opacified cornea. ${ }^{13,14}$ This permits precise focusing of a $3 \mu \mathrm{m}$ spot, accurate to within $5 \mu \mathrm{m}$ inside the anterior chamber. ${ }^{12}$ Second, although argon, excimer, and Nd:YAG lasers involve nanosecond $\left(10^{-9} \mathrm{~s}\right)$ pulses, the Nd:glass FSL employs an ultrafast pulse time of $10^{-15} \mathrm{~s}$. This allows far smaller amounts of energy to be used while maintaining similar power output. The benefit of these features in ophthalmic microsurgery is that it spares delicate, adjacent tissues from collateral damage-a problem, which has hampered the use of other, longer wavelength laser systems.

\section{Photodisruption}

As with the Nd:YAG laser, FSL cuts tissue through a process of photodisruption (in contrast to excimer and argon lasers that use photoablation and photocoagulation, respectively ${ }^{10}$ ). The highly focused FSL increases the power density at the target, leading to the light energy being absorbed by optically clear tissue. This generates a plasma of free electrons and ionised molecules that rapidly expand and collapse, causing microcavitation bubbles and an acoustic shock wave that separate and incise the target tissue. ${ }^{13,15}$ In contrast with Nd:YAG lasers, the microcavitation bubbles produced with FSL are much smaller, hence the reduced collateral damage. ${ }^{13}$

\section{The procedure}

The four main FLACS platforms vary slightly in their specifics (see Table 1), but the basic procedure is consistent throughout, involving four unique steps, ${ }^{10}$ as well as standard pupillary dilatation and topical anaesthesia with or without mild sedation. 
Table 1 Comparison of femtosecond laser-assisted cataract surgery (FLACS) platforms

\begin{tabular}{|c|c|c|c|c|c|}
\hline $\begin{array}{l}\text { Name of } \\
\text { platform }\end{array}$ & Company & $\begin{array}{l}\text { Corneal section/ } \\
\text { capsulotomy/lens } \\
\text { fragmentation }\end{array}$ & Mode of docking & $\begin{array}{l}\text { Docking time } \\
\text { (approx.) }\end{array}$ & $\begin{array}{l}\text { FDA/CE } \\
\text { approved }\end{array}$ \\
\hline Lens $S x$ & $\begin{array}{l}\text { Alcon, Alisa- } \\
\text { Viejo, CA, USA }\end{array}$ & Yes & $\begin{array}{l}\text { Motorised servocontrolled head with a } \\
\text { non-applanating suction fixation device }\end{array}$ & a & FDA and CE \\
\hline LensAR & $\begin{array}{l}\text { LensAR, } \\
\text { Orlando, FL, } \\
\text { USA }\end{array}$ & Yes & $\begin{array}{l}\text { Two piece non-contact docking system } \\
\text { with single-pieced curved patient } \\
\text { interface and vacuum device }\end{array}$ & $3 \mathrm{~min}, 30 \mathrm{~s}$ & $\begin{array}{l}\text { FDA and CE } \\
\text { (capsulotomy and lens } \\
\text { fragmentation) }\end{array}$ \\
\hline VICTUS & $\begin{array}{l}\text { Technolas } \\
\text { perfect vision, } \\
\text { Bausch and } \\
\text { Lomb }\end{array}$ & Yes & Curved patient interface & $2 \min$ & $\begin{array}{l}\text { FDA (capsulotomy) and CE } \\
\text { (corneal section, capsulotomy } \\
\text { and lens fragmentation) }\end{array}$ \\
\hline
\end{tabular}

a Information unavailable at time of publication.

\section{Preoperative planning for FLACS surgery}

First, detailed planning of each stage of the operation is required. This involves assessing the anatomy of the patient's eye, taking into account pupil diameter, anterior chamber depth, and thickness of the lens and cornea.

Size, shape, and centration of the capsulotomy are then calculated, with the choice of IOL in mind. The type of lens fragmentation or liquefaction is chosen and customised by the surgeon, as this will have a bearing on the amount of phaco time and power, which is required subsequently. Parameters for the location, structure, and depth of the clear corneal incisions (CCIs) are inputted. If astigmatic relieving incisions are to be performed, their depth, length, and axis are currently determined by traditional nomograms. However, as femtosecond technology develops, these nomograms will require modification and this is currently being worked on. ${ }^{16}$

\section{Docking the eye}

After the planning stage is complete, the patient's eye is docked into the laser platform in a method similar to that which is used in laser refractive surgery. Docking of the eye into the LASIK interface is known to cause a significant rise in intraocular pressure, in the order of $\geq 80 \mathrm{~mm} \mathrm{Hg} .{ }^{17,18}$ Although this has been linked to complications such as LASIK-induced optic neuropathy, ${ }^{19}$ it is generally well tolerated by the younger refractive surgery population. ${ }^{10}$ However, this rise in intraocular pressure is likely to be more problematic in elderly cataract patients, with the risk of ischaemic retinal and optic nerve injury. In particular, patients with advanced glaucoma may be at risk of 'snuff-out'. For this reason, the developers of FLACS platforms have been compelled to devise alternative methods of stabilising the patient's eye within the optical system, while reducing intraocular pressure rise and anatomical distortion. LenSx uses a curved contact lens, which applanates the cornea and produces an IOP rise of up to $40 \mathrm{~mm} \mathrm{Hg} .{ }^{20}$ OptiMedica's LiquidOptics interface has been found to generate an intraocular pressure rise of $15 \mathrm{~mm} \mathrm{Hg} .{ }^{21}$ Both OptiMedica and LensAR have developed no-touch, non-applanating systems, which employ a liquid interface between the laser system and the eye. ${ }^{10}$ This prevents the formation of corneal folds, which can interfere with laser delivery. Maintaining a highly focused laser in this way allows lower energy levels to be used, with less collateral damage and consequently better results.

\section{Intraoperative anterior segment imaging}

The third step in the procedure involves high-resolution, three-dimensional, wide-field imaging of the anterior segment. Detailed visualisation of the cornea, iris, iridocorneal angle, and lens (including anterior and posterior capsule) is the key to success and safety with FLACS. Inaccuracy at this stage increases the risk of incomplete capsulotomy, imprecise corneal incisions, damage to the iris, and posterior capsular rupture. Two systems have been developed for this purpose, with LenSx, Catalys (Optimedica), and VICTUS (Technolas Perfect Vision) utilising Fourier-domain optical coherence tomography and LensAR employing a confocal structured illumination-scanning transmitter system similar to the Scheimpflug imaging systems developed for corneal topography. ${ }^{2,22-24}$

\section{The treatment stage}

Following docking and visualisation, the treatment stage is initiated. Each laser incision is constructed in the posteroanterior plane, a principle that elegantly employs the posterior microcavitation bubbles to scatter the laser beam and reduce the amount of energy reaching the 
retina. ${ }^{14}$ By keeping the bubbles posterior to the laser target, the focus of the laser beam is maintained and this avoids scatter before the target tissue. ${ }^{14}$ The sequence of incision creation varies between the available FLACS platforms and although theoretical differences exist, there is currently insufficient evidence to suggest which order has superiority. After the laser incisions have been created, lens removal and IOL implantation are performed under sterile conditions, ideally without moving the patient. With Optimedica and LensAR systems, the patient is usually maintained in the same room with the machine moved away; however, the LenSx and VICTUS platforms come with a patient bed in order for patient transfer.

\section{Applications and potential benefits}

Femtosecond laser currently has four applications in cataract surgery: astigmatic limbal relaxing incisions (LRIs), corneal wound construction, anterior capsulotomy (or laser-incised capsulorhexis), and lens fragmentation. ${ }^{10}$ It is envisaged that the introduction of femtosecond laser in these four domains will lead to cataract surgery becoming faster and safer, with better visual outcomes. ${ }^{25}$

\section{Limbal relaxing incisions}

A potential application of FLACS is in the creation of highly accurate, reliable astigmatic LRIs. Manual LRIs can be technically challenging, with many surgeons reluctant to perform them due to concerns related to inaccuracy and the small risk of corneal perforation. Therefore, only a small proportion of patients who could benefit from LRIs are actually receiving them. ${ }^{10}$

Femtosecond laser-assisted LRIs may allow for optimum correction of low astigmatism, rendering conventional and somewhat unpredictable, manual LRIs obsolete. For higher degrees of astigmatism, however, it is likely that toric IOLs will continue to represent the best treatment modality.

\section{Corneal wound construction}

The self-sealing CCI, used by the majority of cataract surgeons to gain access to the anterior chamber, ${ }^{26}$ is another aspect of cataract surgery which femtosecond technology aims to improve. The length and shape of the incisions are important factors in corneal wound safety, with square surface architecture being associated with less wound leakage $\mathrm{e}^{27,28}$ and consequently a lower risk of hypotony, iris prolapse, and endophthalmitis. A wellconstructed three-step CCI reduces the risk of 'wound slippage', which can result in induced astigmatism.
Damage to Descemet's membrane and gaping at the internal aspect of the corneal wound are also commonly found with manual CCIs. ${ }^{29}$ This can lead to delayed healing and an increased risk of corneal decompensation. ${ }^{30}$

Masket et $a l^{28}$ demonstrated greater architectural stability and reproducibility with corneal incisions in cadaveric eyes created with the femtosecond laser. Using indentation with ophthalmodynamometry, FSL incisions measuring $3.0 \times 2.0 \mathrm{~mm}$ were found not to leak at any level of external pressure..$^{28}$ More rectangular incisions $(3.0 \times 1.0 \mathrm{~mm})$ leaked with all levels of external pressure. ${ }^{28}$ However, conclusions from this pilot study were limited by the small sample size and the fact that cadaveric eyes were used. In a subsequent in vivo study of 50 human eyes, Palanker et $a l^{14}$ employed multiplanar corneal incisions, which were self-sealing and resistant to leakage under physiological intraocular pressure. It is thought that this, combined with a reduction in the mechanical stress exerted on the eye during the FLACS procedure, will lead to faster healing and fewer CCIrelated complications. Longer follow-up data are required to add evidence to these hypotheses.

\section{Anterior capsulotomy}

Several studies have increased the understanding of the importance of the anterior capsulotomy. Its size and circularity is one of the key determinants of the positioning and performance of the IOL. If the capsulotomy is too small, fibrosis and hyperopic shift may ensue. ${ }^{31}$ Conversely, if too large or asymmetric, the IOL may be adversely affected by tilt, rotation, decentration, myopic shift, and posterior capsular opacification..$^{21,32,33}$ The capsulotomy is also closely related to the effective lens position (ELP) and it has been found that imprecise estimation of the ELP is the single biggest cause of inaccurate IOL power calculation. ${ }^{34,35}$ Tilt, rotation, decentration, and changes in ELP may have even more profound effects with toric, accommodating and multifocal IOLs. ${ }^{36}$ All of these factors have implications for the final refractive outcome, while also increasing the risk of aberrations such as astigmatism, halo and coma. ${ }^{37}$ Ideally, the capsulotomy should be perfectly circular and overlapping the IOL optic by $0.5 \mathrm{~mm}$ for 360 degrees. ${ }^{21}$

These factors are of great significance when considering the newest IOL designs. One example is the dual-optic accommodating IOL, whose accommodative ability depends on movement of the anterior optic with ciliary contraction and relaxation. This relies on the IOL being fully overlapped by the anterior capsule, without which the anterior optic may prolapse out of the capsular bag. ${ }^{38,39}$ The remarkable potential of these more complex 
IOLs may not be fully realised with the current limitations imposed by the relative imprecision of the manual capsulorhexis. Indeed, a suboptimal capsulorhexis is a relative contraindication to the implanting of an accommodative IOL.

Constructing the anterior capsulorhexis manually is technically challenging and recognised as one of the most difficult aspects of cataract surgery to learn. ${ }^{40}$ Despite this, it remains unenhanced by advances in technology and is still dependent on freehand, circular tearing by the surgeon. It is estimated that the manual capsulorhexis is complicated by capsular tears in $1 \%$ cases $^{2}$ and its complexity increases in cases involving shallow anterior chambers, paediatric/mature cataracts, fibrosed capsules, weak zonules or poor visibility. ${ }^{21,41}$ Although cataract surgeons may previously have been satisfied by completing the capsulorhexis safely, the emphasis is now shifting towards completing the procedure with greater accuracy in terms of shape, centration and diameter.

Most surgeons currently use anatomical landmarks such as the pupillary margin to guide the placement of the capsulorhexis. Owing to factors such as irregular pupillary dilation, differences in corneal magnification and other anatomical variants, these landmarks are not always reliable. Studies have shown that even in the hands of an experienced cataract surgeon, there is considerable variability in the construction of the manual capsulorhexis. ${ }^{2,21}$ In their landmark study from 2009, which evaluated the LenSx platform, Nagy et $a l^{2}$ demonstrated FSL capsulotomies to be significantly more accurate and reproducible in terms of size, circularity and centration than manual capsulorhexes. In this study, those measuring circularity and centration were not blinded as to whether FLACS or conventional phacoemulsification had been performed. Although this introduces a risk of bias, similar conclusions have since been reached by several other studies. ${ }^{14,21,28,42-45}$

An anterior capsule that completely overlaps the optic of the IOL is known to reduce the risk of posterior capsular opacification, improve IOL centration and

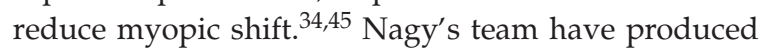
statistically significantly lower rates of incomplete capsulotomy-IOL overlap with FLACS $(6 / 54 ; 11 \%)$ when compared with conventional cataract surgery (16/57; $28 \%$ ), although this study was limited by short follow-up of 1 week and a lack of blinding for the postoperative measurements. ${ }^{45}$ Another conclusion from this study was that the diameter of manual capsulorhexes varied with differences in pupil size, axial length, and magnification from the corneal curvature. ${ }^{45}$ Conversely, capsulotomies performed with femtosecond laser were not influenced by these variables. ${ }^{45}$ No significant difference in capsulotomy circularity between the laser and manual groups was found in this particular study. ${ }^{45}$
FSL capsulotomies in porcine eyes have been shown to be able to withstand greater amounts of stretch than manual capsulorhexes. ${ }^{2}$ Similar results related to the strength of the capsular edge in porcine eyes have been reported by other authors. ${ }^{14,21,46}$ Whether this increased tensile strength is similar in human eyes and leads to clinically relevant benefits, in terms of lower rates of capsular tear, remains to be seen.

Although there are variations between the LenSx, LensAR and Catalys systems in their capsulotomy results, they are united by increased precision and circularity relative to manual capsulorhexes. ${ }^{44,47,48}$ The LenSx and Catalys systems have also been reported to give improved results for IOL centration when compared with the manual technique. ${ }^{47-49}$ Using LenSx, Kranitz et $a l^{49}$ found the improved IOL centration to remain statistically significant at 1 year postoperatively. In this study, horizontal and vertical IOL centration was found to worsen more over the first year with manual capsulorhexis than with femtosecond capsulotomy (anteroposterior IOL position was not evaluated). This was presumed to be a result of asymmetric capsular contraction, although interestingly the study found no significant difference in circularity between femtosecond capsulotomy and manual CCC after 1 month. The authors concluded that the risk of IOL decentration was six times higher with manual capsulorhexis. ${ }^{49}$ This is particularly important with accommodating and multifocal IOLs, in which it has been found that even slight decentration $(>0.4 \mathrm{~mm})$ can adversely affect optical performance. ${ }^{50}$ Curiously, Kranitz et al ${ }^{49}$ used both three-piece and one-piece spherical, acrylic lenses in their study, but did not specify what influenced the choice of lens. No significant differences were noted between the different lenses in terms of decentration.

New intraocular lenses designed specifically to take advantage of the increased precision of femtosecond technology are already in development. However, there is currently no long-term data to prove the more precise laser capsulotomy ultimately leads to significantly better visual and refractive outcomes than a manual capsulorhexis performed by an experienced surgeon. Particularly with simple, monofocal IOLs, the differences may be unnoticeable.

\section{Lens liquefaction and fragmentation}

Complications in cataract surgery most frequently occur during or because of phacoemulsification itself. ${ }^{51}$ Intraocular manipulation of the rapidly oscillating ultrasound probe at this stage increases the risk of injury to the capsule, iris, and cornea. Thermal injury to the corneal wound may also occur. Furthermore, the risk of endophthalmitis is thought to increase every time an 
instrument is introduced into the eye. ${ }^{52}$ Laboratory and animal studies have shown that ultrasound power within the anterior chamber causes oxidative stress and cellular injury, with the production of free radicals that are toxic to the corneal endothelium. ${ }^{53,54}$ However, the magnitude of this cellular damage in vivo with modern

phacoemulsification techniques is uncertain, so its clinical relevance remains unclear.

FLACS has been designed to pretreat the lens, by using liquefaction or fragmentation patterns to segment the nucleus and soften harder cataracts, ${ }^{10}$ thus decreasing the amount of intraocular instrumentation and movement. Liquefaction has been suggested for refractive lens exchange and softer cataracts (up to LOCS grade 2.0), whereas fragmentation is recommended for harder lenses (up to LOCS grade 4.0). ${ }^{16}$ In porcine studies with the LenSx system, lens fragmentation allowed the surgeon to reduce ultrasound power by $43 \%$, and phacoemulsification time by $51 \% .^{2}$ The authors of this study employed a 'divide and conquer' technique for manual phacoemulsification. Whether such significant contrasts in ultrasound power and phaco time exist with other techniques (eg 'phaco chop') remains to be elucidated. Palanker et al's ${ }^{14}$ randomised case-controlled study of 59 human eyes in vivo found that phacoemulsification energy was reduced by $39 \%$ in eyes treated with FLACS compared with standard cataract surgery. However, the technique used for manual surgery was not specified in this study.

Similar results have been achieved with alternative fragmentation algorithms on different laser platforms. ${ }^{24,55-60}$ One study demonstrated significantly less corneal swelling on the first postoperative day with FLACS, compared with conventional surgery. ${ }^{61}$

Although differences between the two groups did not remain statistically significant at 1 week and 1 month postoperatively, the authors concluded that FLACS may be less traumatic to the corneal endothelium. ${ }^{61}$ This seems promising, but long-term studies are required to determine whether or not laser lens fragmentation significantly improves the safety profile and outcomes of cataract surgery. Efforts are ongoing to determine which fragmentation patterns have superiority in terms of reducing effective phacoemulsification time. ${ }^{62}$ The ultimate objective may be to develop a fragmentation and liquefaction algorithm, which allows the lens to be simply aspirated, obviating the need for ultrasound energy at all.

\section{Outcomes in human studies}

The number of studies of FLACS in human subjects is steadily increasing. So far, good visual outcomes, low complication rates and no significant safety concerns have been reported. In their original study of nine human eyes, Nagy et $a l^{2}$ achieved 20/20 best-corrected visual acuity (BCVA) in all cases at 1 month postoperatively. A larger study undertaken by Edwards et al ${ }^{63}$ compared 60 eyes treated with the LensAR platform, with 45 eyes undergoing conventional cataract surgery. The FLACS group achieved a mean BCVA of $0.05 \pm 0.1 \log$ MAR, whereas the conventional control group achieved $0.03 \pm 0.05 \log$ MAR. This difference did not attain statistical significance. A study of 53 eyes, presented at the 2011 ARVO annual meeting, produced significantly better outcomes with femtosecond capsulotomy over manual capsulorhexis in terms of the mean deviation of spherical equivalent from target refraction. ${ }^{64}$ Further work by Nagy's group has shown that predictability of IOL power calculation is significantly better in a prospective study of FLACS $(n=77)$ compared with conventional cataract surgery $(n=57) .{ }^{65}$ In contrast, a similar study comparing femtosecond capsulotomy ( $n=48)$ with manual capsulorhexis $(n=51)$, found no statistically significant differences in postoperative residual refraction or distance visual acuity. ${ }^{66}$ However, the same study did demonstrate significantly better outcomes in the FLACS group in terms of internal optical aberrations (intraocular vertical tilt, coma and Strehl ratio). ${ }^{66}$ Whether this produces tangible improvements in visual quality which can be appreciated by patients remains to be established.

In a study of 50 eyes treated with the LenSx system and implanted with accommodating IOLs, each eye achieved BCVA of 20/30 or better at 1 week postoperatively. ${ }^{67}$ This study correlated with earlier reports in terms of the accuracy and reproducibility of FSL-corneal incisions. It also demonstrated reduced variation in ELP, decreased surgical manipulation, less ultrasound power and fewer induced optical aberrations. In a separate study of 50 patients, with one eye undergoing FLACS on the Optimedica platform and the fellow eye undergoing conventional surgery, nonstatistically significant differences between the two groups in terms of change in postoperative BCVA were reported. ${ }^{14}$ Another outcome from this study was improved rates of postoperative corneal oedema in the laser group. To address safety aspects of the technology, a sidearm of the same study investigated the effect of maximal FSL settings on the fundi of rabbit eyes. It was found that no retinal damage occurred, as assessed by fundoscopic imaging and fluorescein angiography. ${ }^{14}$

\section{Macular oedema, diabetic maculopathy, and ARMD}

Subclinical macular oedema is a common complication of conventional phacoemulsification. In a study comparing the macular effects of FLACS vs conventional surgery 
with a 'divide and conquer' technique, significantly less thickening of the inner macular ring was found in the FLACS group at 1 week postoperatively (mean difference of $21.68 \mu \mathrm{m}, P<0.001){ }^{20}$ This difference between the FLACS and control groups reduced after 1 month and no longer attained statistical significance, but the authors suggested that reduced subclinical oedema in the early postoperative phase could be beneficial for patients at risk of developing clinically significant cystoid macular oedema later on. ${ }^{20}$ No statistically significant differences between the two groups were found in terms of foveal thickness, total macular volume, or outer macular ring thickness. ${ }^{20}$ A subsequent study demonstrated the presence of subclinical macular oedema in eyes undergoing FLACS $(n=12)$ and conventional surgery $(n=13)$, predominantly in the outer nuclear layer (ONL), which comprises the photoreceptors. ${ }^{68}$ It is thought that this macular thickening is related to inflammation mediated by prostaglandins and triggered by manipulation of the anterior segment, particularly the iris. $^{20,68}$ Interestingly, the relative ONL: total retina ratio was significantly less in the FLACS group in both the inner macular ring (0.26 vs 0.28 ) and the outer macular ring (0.27 vs 0.29). ${ }^{68}$ No significant difference in visual acuity was found between the two groups, but this study was limited by small numbers.

These findings may be relevant when considering patients deemed to be at high risk of developing postoperative inflammation, cystoid macular oedema, and diabetic maculopathy. However, both of the aforementioned studies were limited by small numbers and short follow-up periods of 1 month and 4-8 weeks, respectively, so larger, longer-term studies are required to fully investigate this potential benefit. Little is known about the effects of FLACS on age-related macular degeneration (ARMD), although one could infer that a reduced inflammatory response in the eye may decrease the risk of ARMD progression.

\section{Complex cataract cases}

FLACS is possible, and may even help improve outcomes, in trauma cases with white cataract formation or anterior capsule rupture. ${ }^{69}$ Anterior capsular lacerations complicate the construction of the manual capsulorhexis, but the increased delicacy and accuracy of femtosecond lasers may be able to overcome this. However, the high precision of FLACS does currently depend on a stable lens and so lens fragmentation may not be an option if phacodonesis has occurred as a consequence of trauma. Similarly, unstable lenses in the context of pseudoexfoliation or zonular dialysis may also be a relative contraindication.
Although the majority of studies to date have focused on improving refractive outcomes in relatively low-risk patients, as the technology develops and limitations are addressed, it could be found that FLACS is the method of choice for dealing with difficult cataracts at high risk of corneal, capsular, zonular, or retinal problems.

\section{Practicalities and limitations}

\section{The docking process}

The FLACS platforms are strongly reliant upon the compliance and other characteristics of patients. Poor mobility, tremor, an inability to lie flat, deep set eyes, and narrow palpebral apertures may impair the docking process and therefore are relative contraindications. Indeed, in a study of 200 eyes undergoing FLACS, the mean number of docking attempts was 1.5, although this decreased as the surgeons' experience increased. ${ }^{70}$ Occasionally, a loss of suction can occur after the eye has been docked. Bali et al $7^{70}$ encountered this in 5 of 200 eyes, but in each case the footswitch was released and the laser was not initiated. It has been suggested that movement of redundant conjunctiva, or the appearance of a meniscus, may alert the operating surgeon to an impending loss of suction.

\section{Corneal limitations}

Corneal incisions are currently designed to be incomplete, so the anterior chamber is not breached before the patient enters the operating theatre and the ocular surface and adnexae are sterilised. Although no cases of endophthalmitis have so far been reported following FLACS, protocols regarding ocular surface sterilisation have yet to be established. Conceivably, microorganism entrapment could occur within the corneal incision, which is then opened with a microkeratome or blunt spatula. ${ }^{14,16}$

Corneal opacification may hamper absorption of the laser, and therefore affect the quality of corneal incisions. Similarly, it may result in dispersion of laser energy, although the extent of corneal opacification and oedema through which FSL can pass without significant scatter is not yet known. ${ }^{14}$ Although the corneal incisions aim to be self-sealing, stromal hydration may still be required, particularly during the learning curve. ${ }^{16}$

\section{Capsular complications}

FSL capsulotomy requires pupillary dilatation in the order of 7-8 mm, and therefore marked corectopia, poor dilatation, and posterior synechiae are relative contraindications. ${ }^{16}$ In addition, FLACS has been associated with an increased risk of capsular block 
syndrome (CBS), in which posterior capsule rupture (PCR) and lens dislocation occurs following hydrodissection. ${ }^{71}$ In Roberts et al's ${ }^{71}$ series of the first 50 patients undergoing FLACS at their facility, two eyes were complicated by intraoperative CBS. The theory behind this is that FSL lens fragmentation results in intralenticular gas, which expands the nuclear volume. The near-perfect edge of the FSL capsulotomy is then thought to form a seal around the expanded nucleus. This restricts the flow of fluid around the lens, resulting in posterior pressure on the capsule and posterior capsular rupture. It should be noted that, with adjustments to the technique and increased awareness of the risk of CBS, no further cases have occurred at this particular facility. ${ }^{71}$

Bali et al' $^{\prime 0}$ study of their first 200 patients undergoing FLACS on the LenSx platform highlighted the learning curve associated with FLACS and revealed interesting findings relating to the capsulotomy. Once created, the capsulotomy is relatively straightforward to remove, with all patients scoring 8 out of 10 when capsulotomies were ranked on a 1-10 scale according to ease of removal. ${ }^{70}$ Indeed, 17.5\% (35/200), developed free capsulotomies requiring no manual detachment after FSL treatment, and this number increased significantly with the learning curve. ${ }^{70}$ In $10.5 \%$ (21/200), the presence of small anterior capsular tags was noted, which led to anterior capsular tears in $4 \%(8 / 200){ }^{70}$ These extended posteriorly in four eyes, with three requiring anterior vitrectomy and all four needing sulcus implantation of the IOL. ${ }^{70}$ This anterior capsular tear rate of $4 \%$ compares with other studies of conventional cataract surgery, which have demonstrated rates of $3.8 \%$ and $4.7-5.3 \% .{ }^{72,73}$ This study of FLACS also gave an overall incidence of $3.5 \%$ for PCR and $2 \%$ for posterior lens dislocation, although there was a trend towards fewer complications with time, and fewer complications among surgeons with previous experience with femtosecond lasers. ${ }^{70}$ These figures may seem high when compared with those commonly quoted for conventional phacoemulsification. The United Kingdom Cataract National Dataset audit found the combined rate of zonular or PCR to be $1.92 \% .{ }^{74}$ However, it should be emphasised that Bali et al's report described the learning curve of FLACS - a feature of all new techniques, including phacoemulsification itself when it was introduced. For comparison, a similar description of the phacoemulsification learning curve reported an initial $4 \%$ rate of vitreous loss, which subsequently fell to $0.7 \%$ over the course of the author's first 3000 cases. $^{75}$

\section{Grade of cataract}

At present, limitations exist regarding the nature of cataracts that can be treated. Lens fragmentation has an upper limit of capability of LOCS grade 4.0 cataracts, therefore brunescent cataracts may require conventional phacoemulsification, or even extracapsular cataract surgery. Posterior subcapsular cataracts may also rely upon an alternative approach, as the safety margin for FLACS has been suggested as at least $400 \mu \mathrm{m}$ from the posterior capsule. ${ }^{16}$

\section{Surgical time}

In the experience of Bali et $a l,{ }^{70}$ the average time spent in theatre was $18.30 \pm 5.1 \mathrm{~min}(n=200)$, comparing closely to conventional phacoemulsification, where an average time of $15.66 \pm 3.10 \mathrm{~min}$ was spent per case in the control group.

\section{Training implications and the learning curve}

FLACS will certainly require a period of training under supervision, just as with phacoemulsification. Surgeons will need to learn to dock the eye to the laser, as well as understand how to interpret the anatomical images, adjust the laser parameters and deliver energy safely. As demonstrated by Bali et al and as was the case with phacoemulsification, the FLACS technique will involve a significant learning curve-even for experienced cataract surgeons. Each machine is likely to have specific alterations that will require a period of learning by the attending surgeon. Furthermore, with training programmes throughout the world adopting a more competency-based structure, standards across different platforms would have to be considered and adopted by regulatory training boards.

One suggested concern with the development of FLACS is that of a 'loss' of surgical skills, particularly in view of the limitations of the technology. It should be emphasised that FLACS was designed to improve safety and efficacy, but not to replace highly trained surgeons with lesser-skilled technicians. A competent surgeon would still be essential in managing potential complications or irregularities with the laser system. It has also been highlighted that the critical factor of surgical judgement and experience simply cannot be coded into laser software. ${ }^{76}$

A useful parallel here is the transition between extracapsular cataract surgery and phacoemulsification. In the current surgical climate of the west, an extracapsular procedure is now performed extremely rarely, with subsequent exposure for trainee surgeons limited. Even if FLACS becomes widespread, there is still likely to be a need for conventional phacoemulsification in complicated eyes with ocular co-morbidities such as pseudoexfoliation, traumatic phacodonesis, or pupillary sphincter ischaemia due to diabetes. 
Overall, FLACS may allow less-experienced surgeons to obtain better results, but may fail to demonstrate a significant improvement for experienced cataract surgeons not implanting premium intraocular lenses. It is therefore likely to 'flatten the curve', with surgeons attaining similar outcomes across the board.

\section{Economics and financial considerations}

Despite its perceived benefits, FLACS is not yet widespread, even in high-volume refractive centres. This is largely due to the significant financial costs involved in its implementation. Although costs are likely to reduce with competition and more entrants to the market, it is probable that the initial cost of the FLACS platform itself will be between US\$400 000 and $\$ 500000 .{ }^{77}$ Furthermore, a usage fee is likely to be $\$ 150$ to $\$ 400$ per eye and maintenance costs are estimated to be around \$40-50000 per year. ${ }^{77}$ If surgeons are confident in their own microsurgical skills and outcomes, it could be difficult to justify the additional expense, except perhaps in a very high-volume refractive cataract practice.

In a state-funded healthcare system, without the use of premium intraocular lenses, the use of FLACS will no doubt be questioned. The current NHS Tariff to perform cataract surgery is $£ 704 .{ }^{78}$ The benefit of doing a capsulotomy using a $£ 500000$ laser compared with a needle costing a few pence must correlate with the proportional benefit in outcome. At the present time, outside of toric and accommodative IOL use, this does not exist and consequently there is, so far, no reimbursement scheme from either private medical insurance or national health systems. ${ }^{79}$

However, with time and marketing, it is likely that the public perception will change. As awareness of femtosecond technology increases, we will start to experience more and more patients asking about or demanding FLACS. This may necessitate a change in the state-funded healthcare system to allow top-up care, where patients are given the option of paying extra for the premium IOL and laser technology. A system of 'co-payments' such as this is already permitted in some European countries, but not currently in the United Kingdom. Another method of improving economic viability may be through 'bundled discounts', whereby companies reduce the cost of their laser machines in return for a supply contract for other surgical instruments and IOLs. ${ }^{77}$

From a practical viewpoint, the implementation of FLACS in the NHS would require a complete system redesign of existing cataract surgery pathways. The consent process, often conducted by senior nurse practitioners in high-volume units, may need to be replaced, at least in the early stages, by a detailed discussion by the operating surgeon. It has been suggested that surgery should not be conducted on the same day as preoperative assessment. ${ }^{16}$ Operating theatre space would have to be created to fit the laser, with extra space required to allow transfer of either the patient or the phacoemulsification machine to permit the second stage of the operation. It is thought that there is a window of opportunity lasting $2-3 \mathrm{~h}$ after femtosecond capsulotomy, before leaking lens proteins elicit an anterior chamber inflammatory reaction. Therefore, to improve efficiency, two or three patients could be pretreated with the FLACS system before lens removal and IOL implantation in the operating theatre. ${ }^{16}$ One model has been proposed, whereby a single laser suite, operated by one surgeon, feeds into several operating theatres with other surgeons completing the manual parts of the procedure. ${ }^{79} \mathrm{~A}$ situation could result where cataract surgery is no longer performed in smaller hospitals or outreach theatres, with it instead becoming centralised using a 'carousel' model in larger units with access to femtosecond technology. If superior efficacy and safety profile can be demonstrated conclusively, it is conceivable that FLACS may eventually have a role in the management of complex cataracts within the public sector.

\section{The shifting of patient expectations}

It is suggested that following NHS cataract surgery in the UK, 55\% cases should be within 0.50 dioptre of their target postoperative refraction, and $85 \%$ within 1.00 dioptre. ${ }^{80}$ However, as with all branches of medicine and surgery, the expectations and demands of patients are changing. With rapidly advancing IOL technology and an increasing emphasis on achieving near emmetropia, tolerance of less than perfect visual and refractive outcomes is decreasing among patients and surgeons alike. Cataract surgery is being transformed into a refractive operation, and is now the most common procedure to correct refractive errors, being performed five times more frequently than corneal refractive treatments. 8

Unfortunately, the limitations of currently available biometry and surgical techniques mean that the full potential of toric, multifocal, and accommodating IOLs may not reliably be achieved. Several authors have suggested that FLACS may provide the solution to this dilemma, as well as improving the results of standard cataract surgery, which are highly dependent on the skill and experience of the surgeon. ${ }^{2,10,14,21}$ If significantly improved outcomes and safety can be demonstrated, it is possible that FLACS may become the gold standard in years to come. ${ }^{10}$ 


\section{The journey to FLACS}

A false dawn...?

Little is known regarding the medium and long-term outcomes of FLACS. By virtue of its longer existence, phacoemulsification is still the benchmark of safety, efficacy, and convenience. The cataract and refractive industry is fast evolving, innovative, and consistently striving to reduce the risks of complications and improve the outcomes for patients.

However, similar to all technology, FLACS has its limitations and may not be suitable for every patient. Furthermore, little is known about the in vivo behaviour of different forms of cataract with laser fragmentationdoes a vacuolated cataract behave in the same way as a posterior subcapsular cataract, for example? Skilled cataract surgeons will be needed to operate the FLACS platform and deal with any complications that may arise. In certain circumstances, conversion from FLACS to conventional phacoemulsification surgery may be required.

Many questions remain regarding FLACS and more are likely in the immediate future. Weight would certainly be added to the pro-FLACS argument if the findings from initial studies could be replicated and thus validated by independent groups.

From a technical viewpoint, some debate exists regarding the benefits of laser corneal incisions. Masket's cadaver study certainly highlighted improved structural stability, ${ }^{28}$ but current practice involves a partial thickness incision, which is then completed manually once the patient is sterile. Although this avoids breaching the anterior chamber before the patient is sterile, it may impact on the perceived advantages of the laser incisions.

Enhanced ability in lens fragmentation would minimise the need for additional ultrasound energy, even for the densest cataracts, but the improved outcomes may not be sufficient to justify the extra expense.

\section{... Or new beginnings?}

The use of femtosecond lasers in cataract surgery continues to evolve and with that, its potential applications extend. A case series of eight patients has reported success using FLACS with 25-gauge phacovitrectomy, ${ }^{81}$ which paves the way for combining the technology with other ophthalmic procedures. In patients with corneal opacity, it is conceivable that a femtosecond laser could be employed to create a corneal flap and improve visualisation before proceeding with FLACS.

Currently, there is no known way of preventing cataract formation. Similarly, although attempts have been made, no non-surgical treatment modalities exist in a clinically useful form. However, femtosecond lasers have been demonstrated to 'bleach' the human lens through photolysis, decreasing the amount of yellow pigment and resulting in optical rejuvenation of between 3 and 7 years. ${ }^{82}$ It has been postulated that this may delay the need for cataract surgery by 5 years, leading to a $35 \%$ reduction in surgical volume. ${ }^{83}$

Accurate capsulotomies will improve the precision of intraocular lenses, and the use of decentred intraocular lenses for strabismus is a potential use. ${ }^{84}$ If FLACS gains widespread acceptance, its improved precision and accuracy may pave the way for further advances in IOL design. ${ }^{10}$

Photodisruption with femtosecond laser has been shown not to cause cataractogenesis or loss of lens function. ${ }^{85}$ This opens up the possibility of using FSL technology in lenticular refractive surgery. It has been suggested, through the creation of lenticular incisions acting as gliding planes across collagen fibrils, that an element of accommodation to presbyopic lenses could be restored. ${ }^{85}$

\section{Conclusion}

An absence of randomisation and blinding has affected most studies performed to date. Although this introduces a risk of bias to the results, this is mitigated by the fact that most authors have reached similar conclusions. It should also be noted that these early studies, by definition, are affected by the phenomenon of the learning curve. Better results are likely to be reported as surgeons ascend the curve and refine the technique.

Certainly large scale, phase 3 multicentre randomised controlled trials are required to adequately assess the long-term efficacy and complication rates of FLACS when compared with conventional cataract surgery. Will FLACS prove to be significantly superior in terms of long-term visual and refractive outcomes, or simply non-inferior? Will significantly lower rates of endophthalmitis, dropped nuclei, vitreous loss, and posterior capsular opacification be achieved? Prospective studies to compare FSL astigmatic relieving incisions with manual incisions and toric IOLs will also provide valuable information. It is clear that FLACS does indeed herald progress in modern cataract surgery, but further work is required to demonstrate whether its theoretical benefits are significant and worthy of huge financial investment and system overhaul.

\section{Conflict of interest}

The authors declare no conflict of interest. 


\section{References}

1 Savage-Smith E. The practice of surgery in Islamic lands: myth and reality. Soc Hist Med 2000; 13(2): 307-321.

2 Nagy Z, Takacs A, Filkorn T, Sarayba M. Initial clinical evaluation of an intraocular femtosecond laser in cataract surgery. J Refract Surg 2009; 25: 1053-1060.

3 Aron-Rosa D, Aron JJ, Griesemann M, Thyzel R. Use of the neodymium:YAG laser to open the posterior capsule after lens implant surgery: a preliminary report. J Am Intraocul Implant Soc 1980; 6: 352-354.

4 Krasnov MM. Laser-phakopuncture in the treatment of soft cataracts. Br J Ophthalmol 1975; 59: 96-98.

5 Aron-Rosa DS, Aron JJ. Effect of preoperative YAG laser anterior capsulotomy on the incidence of posterior capsule opacification: ten year follow-up. J Cataract Refract Surg 1992; 18: 559-561.

6 Peyman GA, Katoh N. Effects of an erbium: YAG laser on ocular structures. Int Ophthalmol 1987; 10: 245-253.

7 Dodick JM. Laser phacolysis of the human cataractous lens. Dev Ophthalmol 1991; 22: 58-64.

8 Salomao MQ, Wilson SE. Femtosecond laser in laser in situ keratomileusis. J Cataract Refract Surg 2010; 36: 1024-1032.

9 Feizi S. Femtosecond laser cataract surgery. J Ophth Vis Res 2011; 6(2): 151.

10 He L, Sheehy K, Culbertson W. Femtosecond laser-assisted cataract surgery. Curr Opin Ophthalmol 2011; 22: 43-52.

11 Reggiano-Mello G, Krueger RR. Comparison of commercially available femtosecond lasers in refractive surgery. Expert Rev Ophthalmol 2011; 6(1): 55-65.

12 Kullman G, Pineda II, R. Alternative applications of the femtosecond laser in ophthalmology. Semin Ophthalmol 2010; 25(5-6): 256-264.

13 Soong HK, Malta JB. Femtosecond lasers in ophthalmology. Am J Ophthalmol 2009; 147(2): 189-197.

14 Palanker D, Blumenkranz MS, Andersen D, Wiltberger M, Marcellino G, Gooding P et al. Femtosecond laser-assisted cataract surgery with integrated optical coherence tomography. Sci Trans Med 2010; 2(58):58ra85.

15 Sugar A. Ultrafast (femtosecond) laser refractive surgery. Curr Opin Ophthalmol 2002; 13: 246-249.

16 Nagy ZZ. Advanced technology IOLs in cataract surgery: pearls for successful femtosecond cataract surgery. Int Ophthalmol Clin 2012; 52(2): 103-114.

17 Hernandez-Verdejo JL, Teus MA, Roman JM, Bolivar G. Porcine model to compare real-time intraocular pressure during LASIK with a mechanical microkeratome and femtosecond laser. Invest Ophthalmol Vis Sci 2007; 48: 68-72.

18 Chaurasia SS, Luengo Gimeno F, Tan K, Yu S, Tan DT, Beuerman RW et al. In vivo real-time intraocular pressure variations during LASIK flap creation. Invest Ophthalmol Vis Sci 2010; 51: 4641-4645.

19 Lee AG, Kohnen T, Ebner R, Bennett JL, Miller NR, Carlow TJ et al. Optic neuropathy associated with laser in situ keratomileusis. J Cataract Refract Surg 2000; 26(11): 1581-1584.

20 Ecsedy M, Mihaltz K, Kovacs I, Takacs I, Filkorn T, Nagy ZZ. Effect of femtosecond laser cataract surgery on the macula. J Refract Surg 2011; 27(10): 717-722.

21 Friedman NJ, Palanker DV, Schuele G, Andersen D, Marcellino G, Seibel BS et al. Femtosecond laser capsulotomy. J Cataract Refract Surg 2011; 37: 1189-1198.

22 Konstantopoulos A, Hossain PN, Anderson DF. Recent advances in ophthalmic anterior segment imaging: a new era for ophthalmic diagnosis? Br J Ophthalmol 2007; 91: 551-557

23 Swartz T, Marten L, Wang M. Measuring the cornea: the latest developments in corneal topography. Curr Opin Ophthalmol 2007; 18: 325-333.

24 Slade SG, Culbertson WW, Krueger RR. Femtosecond lasers for refractive cataract surgery. Cataract Refract Surg Today 2010; 67-73.

25 Naranjo-Tackman R. How a femtosecond laser increases safety and precision in cataract surgery? Curr Opin Ophthalmol 2011; 23: 53-57

26 Leaming DV. Practice styles and preferences of ASCRS members: 2002 survey. J Cataract Refract Surg 2003; 29: 1412-1420.

27 Ernest PH, Kiessling LA, Lavery KT. Relative strength of cataract incisions in cadaver eyes. J Cataract Refract Surg 1991; 17: 668-671.

28 Masket S, Sarayba M, Ignacio T, Fram N. Femtosecond laserassisted cataract incisions: architectural stability and reproducibility. J Cataract Refract Surg 2010; 36: 1048-1049.

29 Xia Y, Liu X, Luo L, Zeng Y, Cai X, Zeng M et al. Early changes in the clear cornea incision after phacoemulsification: an anterior segment optical coherence tomography study. Acta Ophthalmol 2009; 87: 764-768.

30 Taban M, Behrens A, Newcomb RL, Nobe MY, Saedi G, Sweet PM et al. Acute endophthalmitis following cataract surgery: a systematic review of the literature. Arch Ophthalmol 2005; 123: 613-620.

31 Sanders DR, Higginbotham RW, Opatowsky IE, Confino J. Hyperopic shift in refraction associated with implantation of the single-piece Collamer intraocular lens. J Cataract Refract Surg 2006; 32: 2110-2112.

32 Ravalico G, Tognetto D, Palomba M, Busatto P, Baccara F. Capsulorhexis size and posterior capsule opacification. J Cataract Refract Surg 1996; 22(1): 98-103.

33 Walkow T, Anders N, Pham DT, Wollensak J. Causes of severe decentration and subluxation of intraocular lenses. Graefes Arch Clin Exp Ophthalmol 1998; 236: 9-12.

34 Cekic O, Batman C. The relationship between capsulorhexis size and anterior chamber depth relation. Ophthalmic Surg Lasers 1999; 30(3): 185-190.

35 Norrby S. Sources of error in intraocular lens power calculation. J Cataract Refract Surg 2008; 34: 368-376.

36 Lakshminarayanan V, Enoch JM, Raasch T, Crawford B, Nygaard RW. Refractive changes induced by intraocular lens tilt and longitudinal displacement. Arch Ophthalmol 1986; 104(1): 90-92.

37 Baumeister M, Buhren J, Kohnen T. Tilt and decentration of spherical and aspheric intraocular lenses: effect on highorder aberrations. J Cataract Refract Surg 2009; 35: 1006-1012.

38 McLeod SD, Vargas LG, Portney V, Ting A. Synchrony dualoptic accommodating intraocular lens. Part 1: optical and biomechanical principles and design considerations. $J$ Cataract Refract Surg 2007; 33: 37-46.

39 Ossma IL, Galvis A, Vargas LG, Trager MJ, Vagefi MR, McLeod SD. Synchrony dual-optic accommodating intraocular lens. Part 2: pilot clinical evaluation. J Cataract Refract Surg 2007; 33(1): 47-52.

40 Dooley IJ, O'Brien PD. Subjective difficulty of each stage of phacoemulsification cataract surgery performed by basic surgical trainees. J Cataract Refract Surg 2006; 32: 604-608.

41 Toropygin SG, Krause M, Akkaya A, Riemann I, Seitz B, Mestres $\mathrm{P}$ et al. Experimental femtosecond laser-assisted 
nanosurgery of anterior lens capsule. Eur J Ophthalmol 2011; 21(3): 237-242.

42 Tackman RN, Kuri JV, Nichamin LD, Edwards K. Anterior capsulotomy with an ultrashort pulse laser. J Cataract Refract Surg 2011; 37(5): 819-824.

43 Yeilding RH, Villar-Kuri J, Naranjo-Tackman R, Stangogiannis E, Martinez Y, Garcia S et al. Evaluation of size and shape of anterior lens capsules after photodisruption laser capsulotomy and continuous curvilinear capsulorrhexis. Invest Ophthalmol Vis Sci 2009; 50, E-abstract 5394

44 Nichamin LD, Naranjo Tackman R, Villar Kuri J, Fishkind W. Laser capsulotomy with the LensAR laser system [abstract]. In: Program and Abstracts of XXVIII Congress of the ESCRS Paris, France: 4-8 September 2010.

45 Nagy ZZ, Kranitz K, Takacs AI, Mihaltz K, Kovacs I, Knorz MC. Comparison of intraocular lens decentration parameters after femtosecond and manual capsulotomies. J Refract Surg 2011; 27(8): 564-569.

46 Frey RW, Teuma EV, O'Suilleabhain D, Elliot D, Downes Jr GR, Downes III GR et al. Evaluation of the mechanical properties of the crystalline lens capsule following photodisruption capsulotomy and continuous curvilinear capsulorrhexis. Invest Ophthalmol Vis Sci 2009; 50, E-abstract 1141.

47 Nagy Z. Comparative analysis of the femtolaser-assisted and manual capsulorhexis during phacoemulsification [abstract]. In: Program and Abstracts of XXVIII Congress of the ESCRS Paris, France: 4-8 September 2010.

48 Batlle J. Prospective study of size and shape accuracy of Optimedica Femtosecond Laser Capsulotomy vs. manual capsulorhexis [abstract]. In: Program and Abstracts of XXVIII Congress of the ESCRS Paris, France: 4-8 September 2010.

49 Kranitz K, Takacs A, Mihaltz K, Kovacs I, Knorz MC, Nagy ZZ. Femtosecond laser capsulotomy and manual continuous curvilinear capsulorrhexis parameters and their effects on intraocular lens centration. J Refract Surg 2011; 27(8): 558-563.

50 Holladay JT, Piers PA, Koranyi G, van der Mooren M, Norrby NE. A new intraocular lens design to reduce spherical aberration of pseudophakic eyes. J Refract Surg 2002; 18(6): 683-691.

51 Bellini LP, Brum GS, Grossi RS, Borowsky C. Cataract surgery complication rates. Ophthalmology 2008; 115: 1432-1433.

52 Kelkar A, Kelkar J, Amuaku W, Kelkar U, Shaikh A. How to prevent endophthalmitis in cataract surgeries? Indian J Ophthalmol 2008; 56(5): 403-407

53 Murano N, Ishizaki M, Sato S, Fukuda Y, Takahashi H. Corneal endothelial cell damage by free radicals associated with ultrasound oscillation. Arch Ophthalmol 2008; 126(6): 816-821.

54 Shin YJ, Nishi Y, Engler C, Kang J, Hashmi S, Jun AS et al. The effect of phacoemulsification energy on the redox state of cultured human corneal endothelial cells. Arch Ophthalmol 2009; 127(4): 435-441.

55 Fishkind W, Uy H, Tackman RN, Kuri JV. Alternative fragmentation patterns in femtosecond laser cataract surgery [abstract]. In: Program and Abstracts of American Society of Cataract and Refractive Surgeons Symposium on Cataract, IOL and Refractive Surgery Boston, Massachusetts: 9-14 April 2010.

56 Koch D, Batlle J, Feliz R, Friedman N, Seibel B. The use of OCT-guided femtosecond laser to facilitate cataract nuclear disassembly and aspiration [abstract]. In: Program and Abstracts of XXVIII Congress of the ESCRS Paris, France: 4-8 September 2010.

57 Frey RW, Edwards K, Naranjo-Tackman R, Villar Kuri J, Quezada N, Bunch T et al. Changes in CDE with laser lens fragmentation compared with standard phacoemulsification cataract surgery. Invest Ophthalmol Vis Sci 2010; 51, E-abstract 5418.

58 Uy HS. Femtosecond laser lens fragmentation for higher grade cataracts. In: Program and Abstracts of the Annual meeting of ISRS Illinois, USA: 15-16 October 2010.

59 Batlle JF, Feliz R, Culbertson WW. OCT-guided femtosecond laser cataract surgery: precision and efficacy. Association for Research in Vision and Ophthalmology Annual Meeting A4694 Poster \#D633; Fort Lauderdale, FL 2011. www.arvo.org.

60 Edwards K, Uy HS, Schneider S. The effect of laser lens fragmentation on use of ultrasound energy in cataract surgery. Association for Research in Vision and Ophthalmology Annual Meeting A4710 Poster \#D768; Fort Lauderdale, FL 2011. www.arvo.org.

61 Takacs AI, Kovacs I, Mihaltz K, Filkorn T, Knorz MC, Nagy ZZ. Central corneal volume and endothelial cell count following femtosecond laser-assisted refractive cataract surgery compared to conventional phacoemulsification. J Refract Surg 2012; 28(6): 387-391.

62 Conrad-Hengerer I, Hengerer FH, Schultz T, Dick HB. Effect of femtosecond laser fragmentation of the nucleus with different softening grid sizes on effective phaco time in cataract surgery. J Cataract Refract Surg 2012; 38: 1888-1894.

63 Edwards KH, Frey RW, Naranjo-Tackman R, Villar Kuri J, Quezada N, Bunch T. Clinical outcomes following laser cataract surgery. Invest Ophthalmol Vis Sci 2010; 51, E-abstract 5394.

64 Uy HS, Hill W, Edwards KH. Refractive results after laser anterior capsulotomy. Association for Research in Vision and Ophthalmology Annual Meeting A4695 Poster \#D634; Fort Lauderdale, FL 2011. www.arvo.org.

65 Filkorn T, Kovacs I, Takacs A, Horvath E, Knorz MC, Nagy ZZ. Comparison of IOL power calculation and refractive outcome after laser refractive cataract surgery with a femtosecond laser versus conventional phacoemulsification. J Refract Surg 2012; 28(8): 540-544.

66 Mihaltz K, Knorz MC, Alio K, Takacs AI, Kranitz K, Kovacs I et al. Internal aberrations and optical quality after femtosecond laser anterior capsulotomy in cataract surgery. J Refract Surg 2011; 27(10): 711-716.

67 Slade SG. First 50 accommodating IOLs with an imageguided femtosecond laser in cataract surgery. In: Program and Abstracts of the Annual Meeting of the ISRS Illinois, USA: 15-16 October 2010.

68 Nagy ZZ, Ecsedy M, Kovacs I, Takacs A, Tatrai E, Somfai GM et al. Macular morphology assessed by optical coherence tomography image segmentation after femtosecond laser-assisted and standard cataract surgery. J Cataract Refract Surg 2012; 38(6): 941-946.

69 Nagy ZZ, Kranitz K, Takacs A, Filkorn T, Gergely R, Knorz MC. Intraocular femtosecond laser use in traumatic cataracts following penetrating and blunt trauma. J Refract Surg 2012; 28(2): 151-153.

70 Bali SJ, Hodge C, Lawless M, Roberts TV, Sutton G. Early experience with the femtosecond laser for cataract surgery. Ophthalmology 2012; 119(5): 891-899.

71 Roberts TV, Sutton G, Lawless MA, Jindal-Bali S, Hodge C. Capsular block syndrome associated with femtosecond 
laser-assisted cataract surgery. J Cataract Refract Surg 2011; 37(11): 2068-2070.

72 Ng DT, Rowe NA, Francis IC, Kappagoda MB, Haylen MJ, Schumacher RS et al. Intraoperative complications of 1000 phacoemulsification procedures: a prospective study. J Cataract Refract Surg 1998; 24: 1390-1395.

73 Unal M, Yucel I, Sarici A, Artunay O, Devranoglu K, Akar Y et al. Phacoemulsification with topical anesthesia: resident experience. J Cataract Refract Surg 2006; 32: 1361-1365.

74 Jaycock P, Johnston RL, Taylor H, Adams M, Tole DM, Galloway $\mathrm{P}$ et al. The Cataract National Dataset electronic multi-centre audit of 55,567 operations: updating benchmark standards of care in the United Kingdom and internationally. Eye 2009; 23: 38-49.

75 Martin KR, Burton RL. The phacoemulsification learning curve: per-operative complications in the first 3000 cases of an experienced surgeon. Eye 2000; 14: 190-195.

76 Devgan U. Femtosecond laser-assisted cataract surgery promising but still evolving. Ocular Surg News 2012; 30(2): 41

77 Bethke W. Can you afford to do a femtosecond cataract? Rev Ophthalmol Online 2011; 18(4): 52

78 Department of Health. Confirmation of Payment by Results (PbR) arrangements for 2012-2013; 2012 (accessed 03 October 2012). Available from http://www.dh.gov.uk/en/
Publicationsandstatistics/Publications/Publications PolicyAndGuidance/DH_132654.

79 Cimberle M. Femtosecond laser assisted surgery could revolutionize cataract removal in Europe. Ocular Surg News 2012; 23(3): 1.

80 Gale RP, Saldana M, Johnston RL, Zuberbuhler B, McKibbin M. Benchmark standards for refractive outcomes after NHS cataract surgery. Eye 2009; 23: 149-152.

81 Bali SJ, Hodge C, Chen S, Sutton G. Femtosecond laser assisted cataract surgery in phacovitrectomy. Graefes Arch Clin Exp Ophthalmol 2012; 250(10): 1549-1551.

82 Kessel L, Eskildsen L, van der Poel M, Larsen M. Non-invasive bleaching of the human lens by femtosecond laser photolysis. PLoS One 2010; 5(3): e9711.

83 Kessel L. Can we meet the future demands for cataract surgery? Acta Ophthalmol 2011; 89(3): e289-e290

84 Nishimoto H, Shimzu K, Ishikawa H, Uozato H. New approach for treating vertical strabismus: decentered intraocular lenses. J Cataract Refract Surg 2007; 33: 993-998.

85 Krueger RR, Kuszak J, Lubatschowski H, Myers RI, Ripken T, Heisterkamp A. First safety study of femtosecond laser photodisruption in animal lenses: tissue morphology and cataractogenesis. J Cataract Refract Surg 2005; 31: 2386-2394. 